\title{
Fruit and vegetable contamination with medically important helminths and protozoans in Tarcha town, Dawuro zone, South West Ethiopia
}

This article was published in the following Dove Press journal: Research and Reports in Tropical Medicine

\section{Fitsum Bekele \\ Teha Shumbej}

Department of Medical Laboratory Sciences, College of Medicine and Health Sciences, Wolkite University, Wolkite, Ethiopia
Correspondence: Fitsum Bekele

Department of Medical Laboratory Sciences, College of Medicine and Health Sciences,

Wolkite University, Wolkite, Ethiopia

Tel +25I 91 I76 869 I

Email fbt1019@yahoo.com
Background: Fresh vegetables supply the body with essential supplements. The consumption of raw vegetables and fruits are among the ways for transmission of intestinal parasitic organisms to human beings. This study was aimed at detecting the parasitic contamination in fresh vegetables sold at the central open-aired market of Tarcha town, Ethiopia.

Methods: A total of 270 fresh vegetables and fruit samples were collected from the main market of Tarcha town during August 1, 2017-August 22, 2017. The samples were microscopically examined for detection of medically important parasites after washing with $500 \mathrm{~mL}$ normal saline and 24-hr sedimentation of the washing solution followed by centrifuging at $2000 \mathrm{~g}$ for 5 mins. After centrifugation, the supernatant was decanted leaving the sediment. Finally, the sediment was examined under a light microscope for protozoans and helminths worms.

Results: Of the 270 fresh vegetable and fruit samples, 115 (42.6\%) were found positive for intestinal parasites. A high level of contamination in fresh vegetable and fruit samples was recorded in cabbage $71.1 \%(32 / 45)$ while tomato was the least contaminated $24.4 \%(11 / 45)$. The identified medically important parasites were Entamoeba histolytica/dispar, Giardia intestinalis, Ascaris lumbricoides, Hymenolepis nana, Toxocara spp, Hymenolepis diminuta, and Cystoisospora belli. The most predominant parasite encountered was Ascaris lumbricoides (16.7\%) whereas Cystoisospora belli (2.6\%) the least detected. All of the vegetables and fruits that were contaminated were with more than one parasite species. A statistically significant association between the type of vegetables and the presence of parasites was also observed $(p=0.002)$.

Conclusion: This study has shown that fruits and vegetables which are sold in the study area are highly contaminated with medically important parasites. Fruits and vegetables sold in the study area may play a role in the transmission of intestinal parasitic infections to humans. Effective and comprehensive prevention measures should be taken to ensure food safety. Relevant bodies should work on addressing the issue of high rate of vegetable and fruit contamination in the study area.

Keywords: Parasitic contamination, fruits, vegetables, Tarcha

\section{Background}

Intestinal parasitic infections are among the major global public health problem. Developing countries are prone to the infection because of lack of good sanitation and personal hygiene practices. Moreover, environmental factors such as climate, geography, temperature, soil type, and rainfall also play important roles that contribute to the prevalence of intestinal parasitic infection. ${ }^{1}$ Studies show that infections with parasites of medical importance are related to conditions of poor living, unclean drinking water, poor sanitation, and hygiene. .,3 $^{2,3}$ 
Diseases which are resulting from contaminated food and water are a major cause of morbidity and are still a common threat to public health. Human infections resulting from eating raw fruits and vegetables have increased to an alarming rate during the past decade. ${ }^{4}$

Studies done in Egypt, Libya, Saudi Arabia, Iraq, Iran, the Philippines, and Arbaminch, Ethiopia to assess the role uncooked vegetables and fruits play in the transmission of medically important parasites have stressed that fruits and vegetables, especially consumed raw and unwashed, play a great role in the transmission of protozoans and helminths of clinical importance. ${ }^{5-14}$

Outbreaks of intestinal parasitic infections that were associated with raw vegetables have been reported from developed and developing countries. ${ }^{15,16}$ Malpractices which affect hygiene during planting, harvesting, packing, transportation, and storage of fruits and vegetables can easily expose produces to contamination. ${ }^{14}$

Like many other developing countries, Ethiopians suffer from poor sanitation and low-quality living conditions which make them vulnerable to parasitic infections. Tarcha town is expanding because of the development of mega hydropower projects in the area and the opening of a new university in the town. Reports are also suggesting that the number of tourists visiting the town are increasing which resulted in the opening of many new hotels. Reports from the town trade and industry bureau suggest that fruits and vegetable consumption is increasing.To our knowledge, there is no published document on fruits and vegetable contamination with medically important helminths and protozoans in Tarcha town. Therefore, this study was undertaken to assess fruits and vegetable contamination with medically important helminths and protozoans in this study area.

\section{Methods}

\section{Study setting}

Dawuro Zone is one of the administrative zones in southern Ethiopia. The area is located $500 \mathrm{~km}$ south-west of Addis Ababa, the capital of Ethiopia. The zone exhibits climatic variations from lowland to highland.The administrative town, Tarcha, is situated at $7014^{\circ}$ north latitude and $3705^{\circ}$ east longitude and 1200-1450 m above sea level.

\section{Laboratory examination}

Fruits and vegetables belonging to six different types, which include lettuce, cabbage, carrot, tomato, green pepper, and
Avocado, were purchased from open central market of Tarcha town under normal condition. Equal numbers of samples (45 each, totally 270 samples) were collected.

A portion $(200 \mathrm{~g})$ of each fruit and vegetable was washed separately in $500 \mathrm{~mL}$ of normal saline for detaching diagnostic stages of the parasites such as ova, larvae, cysts, and oocysts of helminths and protozoan parasites commonly assumed to be associated with vegetable contamination. After 24-hr sedimentation of the washing solution, $15 \mathrm{~mL}$ of the sediment was centrifuged at $3,000 \mathrm{rpm}$ for 5 mins. ${ }^{18}$ After centrifugation, the supernatant was decanted leaving the sediment. Finally, the sediment was examined under a light microscope. For identification of oocysts of Cryptosporidium, I.belli, and Cyclospora spp, modified Ziehl-Neelsen staining technique was employed.

\section{Statistical analysis}

Data analysis was performed with SPSS software version 16 (IBM, Chicago, IL, USA). Values were considered to be statistically significant when the calculated $P$-value was equal to or less than 0.05 . Pearson's chi-square test $(\chi 2)$ test was used for assessing categorical variables.

\section{Ethical considerations}

Ethical clearance was obtained from Wolita Sodo University Ethical Review Board. The purpose of the study was explained to the respondents (vendors of fruits and vegetables) prior to data collection.

\section{Results}

Of the total of 270 samples analyzed, 115 samples were found contaminated with at least one type of parasite with a total contamination rate of $42.6 \%$. Contamination with more than one parasite species was observed in the fruit and vegetable samples examined in this study.

Table 1 summarizes infection rate in each sample group analyzed.

The parasites detected included ova of A. lumbricoides, Toxocara spp., Hymenolepis nana, and $H$. diminuta; oocysts Cystoisospora belli; and cysts of $G$. intestinalis and E. histolytica/dispar. Table 2 shows that A. lumbricoides $(16.7 \%)$ was the most frequently detected parasite, followed by Toxocara (13.7\%), Hymenolepis nana $(11.9 \%)$, H. diminuta (10.7\%), E. histolytica/dispar (10.4\%), G. intestinalis (9.6\%), and Cystoisospora belli (2.6\%).

The parasitic contamination rate of the different fruits and vegetables was significantly different $(p=0.002)$ (see Table 3). 
Table I Frequency distribution of parasitological contamination of fruits and vegetables in the central market of Tarcha town from I to 22 March 2017

\begin{tabular}{|c|c|c|c|c|c|c|}
\hline \multirow[t]{2}{*}{ Vegetable type } & \multirow[t]{2}{*}{ Number examined } & \multirow[t]{2}{*}{ Number positive [\%] } & \multicolumn{4}{|c|}{ Number of parasite species detected } \\
\hline & & & One [\%] & Two [\%] & Three [\%] & Four $[\%]$ \\
\hline Tomatoes & 45 & II [24.4] & $8[17.8]$ & $2[4.5]$ & I [2.2] & 0 \\
\hline Lettuce & 45 & $20[44.4]$ & 15 [33.3] & $3[6.7]$ & $2[4.5]$ & 0 \\
\hline Carrot & 45 & 15 [33.3] & $12[26.7]$ & $2[4.5]$ & I [2.2] & 0 \\
\hline Cabbage & 45 & $32[7 \mid .1]$ & $24[53.3]$ & $4[8.9]$ & $3[6.7]$ & $\mathrm{I}[2.2]$ \\
\hline Green pepper & 45 & $20[44.4]$ & $18[40.0]$ & I [2.2] & I [2.2] & 0 \\
\hline Avocado & 45 & 17 [37.8] & 16 [35.6] & I [2.2] & 0 & 0 \\
\hline Total & 270 & 115 [42.6] & 164 [60.7] & 21 [7.8] & 9 [3.3] & $2[0.7]$ \\
\hline
\end{tabular}

Table 2 The number, percentage, and the corresponding parasite density of contaminated fruits and vegetables sold at the central market in Tarcha town from I to 22 March 2017

\begin{tabular}{|c|c|c|c|c|c|c|c|}
\hline \multirow[t]{2}{*}{ Parasite species } & $\begin{array}{l}\text { Tomatoes } \\
n=45\end{array}$ & $\begin{array}{l}\text { Lettuce } \\
n=45\end{array}$ & $\begin{array}{l}\text { Carrot } \\
n=45\end{array}$ & $\begin{array}{l}\text { Cabbage } \\
n=45\end{array}$ & $\begin{array}{l}\text { Green pepper } \\
n=45\end{array}$ & $\begin{array}{l}\text { Avocado } \\
n=45\end{array}$ & $\begin{array}{l}\text { Total } \\
\mathbf{N}=\mathbf{2 7 0}\end{array}$ \\
\hline & $\#(\%)$ & $\#(\%)$ & $\#(\%)$ & $\#(\%)$ & $\#(\%)$ & $\#(\%)$ & \#(\%) \\
\hline Ascaris lumbricoides & $3(6.6)$ & $9(20)$ & $6(13.3)$ & $12(26.7)$ & $9(20)$ & $6(13.3)$ & $45(16.7)$ \\
\hline Toxocara spp. & $2(4.4)$ & $8(17.8)$ & $7(15.6)$ & II (24.4) & $5(I I .1)$ & $4(8.8)$ & $37(13.7)$ \\
\hline Hymenolepis nana & $0(0)$ & $7(15.6)$ & $6(13.3)$ & $8(17.8)$ & $7(15.6)$ & $4(8.8)$ & $32(11.9)$ \\
\hline Entamoeba histolytica/dispar & $\mathrm{I}(2.2)$ & $4(8.8)$ & $6(13.3)$ & $7(15.6)$ & $5(11.1)$ & $5(11.1)$ & $28(10.4)$ \\
\hline Giardia intestinalis & $\mathrm{I}(2.2)$ & $4(8.8)$ & $7(15.6)$ & $8(17.8)$ & $6(13.3)$ & $0(0)$ & $26(9.6)$ \\
\hline H. diminuta & $0(0)$ & $3(6.6)$ & $6(13.3)$ & $7(15.6)$ & $6(13.3)$ & $5(I I . I)$ & $29(10.7)$ \\
\hline Cystoisospora belli & $0(0)$ & $\mathrm{I}(2.2)$ & $2(4.4)$ & $4(8.8)$ & $0(0)$ & $0(0)$ & $7(2.6)$ \\
\hline
\end{tabular}

\section{Discussion}

Fruits and vegetables which are eaten raw or undercooked are an important route of transmission of intestinal parasites and have been shown to be an important source of foodborne outbreaks in developing countries. Ethiopia is among the tropical countries which are highly affected by intestinal parasite infections and the fact that the country has favorable climate and unsanitary conditions that facilitate fecal pollution of water, foodstuffs, and soil have aggravated the problem. ${ }^{3,11}$ Foodborne pathogens are responsible for an increasing burden of disease worldwide. ${ }^{17}$ This study attempted to address the rate of contamination of raw fruits and vegetables, with medically important parasites, in the specified study area. Total parasitic contamination was found to be $42.6 \%$, which is in agreement with results reported from southern Ethiopia and elsewhere. ${ }^{14,15}$ On the other hand, it is lower when compared with the findings of some studies. ${ }^{18-20}$

The disparity between this study and previous ones might be due to the variations which are related to the geographic and environmental condition, the kind of sample, methods used, and socioeconomic status. On condition that the abovementioned factors differ, accordingly the discrepancy of the results would be expected.

Cabbage $(71.1 \%)$ was found to be the most contaminated product with parasites, followed by lettuce and green pepper (44.4\% each), avocado (37.8\%), carrot (33.3\%). Tomato $(24.4 \%)$ was found to be the least contaminated. The variation in contamination between different vegetables and fruits analyzed in this study might be explained by the fact that cabbage and lettuce have larger and uneven surfaces, which help the parasites in attaching to their surface easily whereas the smooth surface of tomato might hinder the rate of parasitic attachment and contribute to the lower contamination rate observed in this study as previously observed. ${ }^{5}$

In the present study, A. lumbricoides was found to be the most detected parasite with a prevalence of $16.7 \%$. Similar to the present study, previous studies conducted in Ethiopia and outside have reported the same finding. ${ }^{11,20}$ The parasite's cosmopolitan nature, the high number of eggs produced by the female parasite, and the strong and resistant nature of the eggs that enable them to survive harsh environment might 
Table 3 Chi-square test of factors associated with parasitic contamination of fruits and vegetables sold in the central Market of Tarcha town from I to 22 March 2017

\begin{tabular}{|l|l|l|l|l|}
\hline \multirow{2}{*}{ Variable } & \multicolumn{3}{|l|}{ Parasitological analysis } \\
\cline { 2 - 5 } & $\#[\%]$ & Total & $\mathbf{X}^{2}$ & p-value \\
\hline Vendors level of education & & & & \\
Formal education & $35[25.9]$ & 135 & 17.6 & 0.003 \\
Illiterate & $80[59.2]$ & 135 & & \\
Total & $115[42.6]$ & 270 & & \\
\hline Type of produce & & & & \\
Tomato & $11[24.4]$ & 45 & & \\
Lettuce & $20[44.4]$ & 45 & & \\
Carrot & $15[33.3]$ & 45 & 13.2 & 0.002 \\
Cabbage & $32[71.1]$ & 45 & & \\
Green pepper & $20[44.4]$ & 45 & & \\
Avocado & $17[37.8]$ & 45 & & \\
Total & $115[42.6]$ & 270 & & \\
\hline Washed before display & & & & \\
Yes & $28[28.0]$ & 100 & & \\
No & $87[51.2]$ & 170 & 7.9 & 0.16 \\
Total & $115[46.2]$ & 270 & & \\
\hline Means of display & & & & \\
On the floor & $77[48.1]$ & 160 & & \multirow{2}{*}{ On top of the table } \\
Total & $38[34.6]$ & 110 & 2.9 & 0.7154 \\
\hline
\end{tabular}

have contributed for this. It is known that the ova can survive in the absence of oxygen, live for 2 years at $5-10^{\circ} \mathrm{C}$, and be unaffected by desiccation for up to 3 weeks. ${ }^{21}$

Toxocara species were the second most observed parasite with the prevalence of $13.7 \%$. Fertility of the female parasite might have contributed to this; it is known that female adults produce up to 10,000 eggs daily, and the egg may survive for up to 10 years resisting harsh environmental conditions. ${ }^{22,23}$

H. nana ranked the third frequently detected parasite in the present study, with a prevalence of $11.9 \%$. Compared to a study done in Jimma (8.3\%) and Banha in Egypt $(2.8 \%)$, the prevalence observed in the present study was higher, climatic variations and the geographic difference might have contributed for the discrepancy observed. ${ }^{18,24}$

Contamination with multiple species of medically important parasites was seen in every kind of fruits and vegetables studied. This might point out the continued existence of intestinal parasitic infections in the area. ${ }^{13}$

Our study has shown that the rate of contamination of fruits and vegetables in our study area is high which needs the attention of relevant bodies. However, it is important to note that our study has limitations. This study did not demonstrate the effect of seasonal variation on parasitic contamination. Because of small number of fruits and vegetables examined, we did not address the comparison of results among the types of produce. So, these factors might affect the rate of vegetable contamination in our study.

\section{Conclusion}

The high contamination rate of fruits and vegetables consumed in Tarcha town indicates that fruits and vegetables may serve as sources for parasitic infections among the community. Washing of fruits and vegetables, health education on improving hygienic practices for vegetable handlers, and improvements in sanitation of the town and its surrounding may help in preventing parasitic contamination.

\section{Data sharing statement}

The datasets analyzed during the current study are available from the corresponding author on reasonable request.

\section{Acknowledgments}

We appreciate and extend our gratitude to the vendors for their willingness and cooperation during the study.

\section{Author contributions}

All authors contributed to data analysis, drafting and revising the article, gave final approval of the version to be published, and agree to be accountable for all aspects of the work.

\section{Disclosure}

The authors report no conflicts of interest in this work.

\section{References}

1. Punsawad C, Phasuk N, Thongtup K, Nagavirochana S, Viriyavejakul P. Prevalence of parasitic contamination of raw vegetables in Nakhon Si Thammarat province, southern Thailand. BMC Public Health. 2019;19(1):34. doi:10.1186/s12889-018-6358-9

2. Okyay P, Ertug S, Gultekin B, Onen O, Beser E. Intestinal parasites prevalence and related factors in school children, a western city sample-Turkey. BMC Public Health. 2004;4:64.

3. Wegayehu T, Tsalla T, Seifu B, Teklu T. Prevalence of intestinal parasitic infections among highland and lowland dwellers in Gamo area, South Ethiopia. BMC Public Health. 2013;13:151. doi:10.1186/ 1471-2458-13-151

4. de W Blackburn C, McClure PJ. Foodborne Pathogens: Hazards, Risk Analysis and Control. Washington DC: CRC Press; 2002:18-19.

5. Said DE. Detection of parasites in commonly consumed raw vegetables. Alexandria J Med. 2012;48:345-352. 
6. Hassan A, Farouk H, Abdul-Ghani R. Parasitological contamination of freshly eaten vegetables collected from local markets in Alexandria, Egypt: a preliminary study: a preliminary study. Food Control. 2012;26(2):500-503.

7. Abougrain AK, Nahaisi MH, Madi NS, Saied MM, Ghenghesh KS. Parasitological contamination in salad vegetables in Tripoli-Libya. Food Control. 2010;21(5):760-762. doi:10.1016/ j.foodcont.2009.11.005

8. Al-Megrin WAI. Prevalence of intestinal parasites in leafy vegetables in Riyadh, Saudi Arabia. Int $J$ Zool Res. 2010;5(2):20-23. doi:10.3923/ijtmed.2010.20.23

9. Hadi AM. Isolation and identification of intestinal parasites from vegetables from different markets of Iraq. Bull Iraq Natural History Museum. 2011;11(4):17-25.

10. Gharavi MJ, Jahani MR, Rokni MB. Parasitic contamination of vegetables from farms and markets in Tehran. Iran J Public Health. 2002;31(4):83-86.

11. Su GL S, Mariano CMR, Matti NSA, Ramos GB. Assessing parasitic infestation of vegetables in selected markets in Metro Manila, Philippines. Asian Pacific J Trop Dis. 2012;2(1):51-54.

12. Shahnazi M, Jafari-Sabet M. Prevalence of parasitic contamination of raw vegetables in villages of Qazvin Province, Iran. Foodborne Pathog Dis. 2010;7(9):1025-1030. doi:10.1089/fpd.2009.0477

13. Omowaye OS, Audu PA. Parasites contamination and distribution on fruits and vegetables in Kogi, Nigeria. CIBTech $J$ Bio-Protocols. 2012;1(1):44-47. Available from: http://www.cibtech.org/cjbp. Accessed June 2017.

14. Bekele F, Tefera T, Biresaw G, Yohannes T. Parasitic contamination of raw vegetables and fruits collected from selected local markets in Arba Minch town, Southern Ethiopia. Infec Dis Poverty. 2017;6:19. doi:10.1186/s40249-016-0226-6

15. Nazemi S, Raei M, Amiri M, Chaman R. Parasitic contamination of raw vegetables in Shahroud, Semnan. Zahedan J Res Med Sci. 2012;14(8):84-86.
16. ul-Haq S, Maqbool A, Javed Khan U, Yasmin G, Sultana R. Parasitic contamination of vegetables eaten raw in Lahore, Pakistan. J Zool. 2014;46(5):1303-1309.

17. Pires SM, Vieira AR, Perez E, Lo F, Wong D, Hald T. Attributing human foodborne illness to food sources and water in Latin America and the Caribbean using data from outbreak investigations. Int J Food Microbiol. 2012;152(3):129-138.

18. Tefera T, Biruksew A, Mekonnen Z, Eshetu T. Parasitic contamination of fruits and vegetables collected from selected local markets of Jimma Town, Southwest Ethiopia. Int Sch Res Notices. 2014. doi:10.1155/2014/382715

19. Ogbolu DO, Alli OA, Ogunleye VF, Olusoga OF, Olaosun I. The presence of intestinal parasites in selected vegetables from open markets in south western Nigeria. Afr J Med Med Sci. 2009;38(4):319-324.

20. Nyarango RM, Aloo PA, Kabiru EW, Nyanchongi BO. The risk of pathogenic Intestinal parasite infections in Kisii Municipality, Kenya. BMC Public Health. 2008;8:237. doi:10.1186/1471-2458-8-237

21. Roberts AD. Ascariasis: introduction and Epidemiology and Transmission. In: Satoskar AR, Simon GL, Hotez PJ, Tsuji M, editors. Medical Parasitology. Austin (Texas): Landes Bioscience; 2009:38-42.

22. Sunil B, Thomas DR, Latha C, Shameem H. Assessment of parasitic contamination of raw vegetables in Mannuthy, Kerala state, India. Vet World. 2014;7(4):253-256. doi:10.14202/vetworld.2014.253-256

23. Klapec T, Borecka A. Contamination of vegetables, fruits and soil with geohelminths eggs on organic farms in Poland. Ann Agric Environ Med. 2012;19(3):421-425.

24. Ahmad Eraky MA, Rashed S, Nasr ME, El-Hamshary M, ElGhannam AS. Parasitic contamination of commonly consumed fresh leafy vegetables in Benha, Egypt. $J$ Parasitol Res. 2014;2014:613960. doi:10.1155/2014/613960
Research and Reports in Tropical Medicine

\section{Publish your work in this journal}

Research and Reports in Tropical Medicine is an international, peerreviewed, open access journal publishing original research, case reports, editorials, reviews and commentaries on all areas of tropical medicine, including: Diseases and medicine in tropical regions; Entomology; Epidemiology; Health economics issues; Infectious disease; Laboratory science and new technology in tropical medicine;
Parasitology; Public health medicine/health care policy in tropical regions; and Microbiology. The manuscript management system is completely online and includes a very quick and fair peer-review system. Visit http://www.dovepress.com/testimonials.php to read real quotes from published authors. 